\title{
Plano de gerenciamento de resíduos sólidos urbanos: estudo de caso em usina de triagem
}

\author{
Plan management of municipal solid waste: a case study on sorting plant \\ Jacson Rodrigues França', Carlos Eduardo Balestrin Flores', Rafael Borth da Silveira', \\ Willian Fernando de Borba', Bruno Acosta Flores', Aline Custódio Ferrão Passini', \\ Pedro Daniel da Cunha Kemerich², Thais Prestes Stein', Alexandre Couto Rodrigues ${ }^{2}$
}

\author{
'Laboratório de Planejamento e Monitoramento Ambiental - LPMA/UFSM, Curso de Engenharia Ambiental da Universidade Federal de \\ Santa Maria - UFSM/CESNORS \\ ${ }^{2}$ Docentes, Curso de Engenharia Ambiental da Universidade Federal de Santa Maria - UFSM/CESNORS
}

\section{Resumo}

O processo de destinação/disposição ambientalmente adequada dos resíduos sólidos urbanos, tem se tornado alvo de pesquisas e incentivos por parte dos órgãos governamentais. Com base nisso, o presente estudo tem por objetivo analisar o sistema de gestão de resíduos sólidos urbanos em uma unidade de triagem, no município de Seberi - RS. A unidade de estudo é um consórcio formado por 30 municípios, que destinam seus resíduos diariamente para o processo de triagem e disposição final ambientalmente adequado. Foi possível perceber que a maior quantidade de materiais presentes no resíduo reciclável é plástico, sendo o município de Frederico Westphalen o que mais contribui diariamente. Com base nisso, foi possível concluir que os municípios consorciados devem investir pesado em um sistema de coleta seletiva, que acarretaria em melhores condições dos materiais recicláveis, aderindo maiores valores e diminuindo os custos de manutenção da unidade.

Palavras-chave: Consórcio público, gestão de resíduos sólidos, triagem.

\begin{abstract}
The process of allocation/environmentally sound disposal of solid waste, has become the subject of research and incentives by the government agencies. Based on this, the present study aims to analyze the management system of municipal solid waste in a triage unit in the municipality of Seberi - RS. The unit of study is a consortium of 30 municipalities, which meant their waste daily to the screening process and environmentally sound disposal. It could be observed that the greatest amount of material present in the waste plastic is recyclable, and the city of Fredericksburg what else contributes daily. Based on this, it was concluded that local consortium must invest heavily in a selective collection system, which would result in better conditions of recyclable materials, adhering highest values and decreasing maintenance costs of the unit.
\end{abstract}




\section{INTRODUÇ̃̃O}

Atualmente, uma das grandes preocupações ambientais está relacionada aos resíduos sólidos gerados pela sociedade moderna e consumista. Com rápido processo industrial, aliada ao crescimento da população e à consequente demanda por bens de consumo, o homem tem produzido quantidades significativas de resíduos, que acabam sendo constituídos de uma mistura muito complexa e de natureza diversa, cujos principais constituintes são: material orgânico, papel, vidro, plástico, dentre outros materiais pesados que possam acarretar na poluição do solo, águas superficiais e subterrâneas.

Segundo ALENCAR (2005), a questão ambiental está se tornando um tema relevante que precisa ser discutido em toda extensão da sociedade civil. Além da discussão, também se faz necessário que sejam empreendidas ações em vários níveis, tais como: individual, empresarial, institucional, governamental, não governamental, local, regional, nacional e internacional.

O aterro sanitário é a forma mais econômica e segura ambientalmente de disposição de resíduos sólidos urbanos. Consiste na utilização de métodos de engenharia para confinar os dejetos na menor área possível, reduzi-los a um menor volume e cobri-los, frequentemente, com uma camada de terra (GARCILASSO, 2006).

Para HIRATA (1993) a construção de aterros de resíduos sólidos tem que obedecer a normas mínimas da Associação Brasileira de Normas Técnicas (ABNT). A obra deverá ser bem localizada em relação aos aquíferos existentes. Estudos hidro geológicos prévios serão necessários e, quando da construção, deverá ser exigida uma camada impermeável inferior de argila de 0,6 a 1,5m de espessura e um recobrimento diário de 0,1 a $0,3 \mathrm{~m}$ de material compactado. Algumas vezes será necessária a colocação de camadas de material sintético (liner), de grande resistência mecânica e química, para garantir a completa vedação hidráulica do empreendimento. Naturalmente, os estratos da zona não saturada deverão ser de material de baixa permeabilidade. Um cuidado especial precisará ser dado aos resíduos recebidos, especificando origem e composição mínima. Drenos superficiais serão necessários para diminuir o ingresso de águas de chuva por escorrimento superficial, no núcleo do aterro.

TARTARI (2005) relata que a disposição de resíduos sem os devidos cuidados pode gerar a proliferação de agentes patogênicos, acarretar na poluição do solo, ar e de recursos hídricos através da migração dos elementos constituintes do chorume e de gases produzidos através do processo de degradação da matéria orgânica desses depósitos.

A gestão dos resíduos sólidos, sua concepção, o equacionamento da geração, do armazenamento, da coleta até a disposição final, são assuntos importantes para a existência de uma Política Nacional de Resíduos Sólidos. Sendo fundamental para disciplinar a gestão integrada, contribuindo para mudança dos padrões de produção e consumo no país, melhoria da qualidade ambiental e das condições de vida da população, assim como para a implementação mais eficaz da Política Nacional do Meio Ambiente e da Política Nacional de Recursos Hídricos.

A preocupação com a questão ambiental torna o gerenciamento de resíduos um processo de extrema importância na preservação da qualidade da saúde e do meio ambiente. A gestão integrada de resíduos deve priorizar a não geração, a minimização da geração e o reaproveitamento dos resíduos, apontando e descrevendo as ações relativas ao seu manejo, visando à minimização na geração de resíduos e suas etapas de manejo a fim de evitar os efeitos negativos sobre o meio ambiente e a saúde pública (PLANO UFPA, 2008).

Além disso, as políticas públicas de desenvolvimento nacional e regional devem incorporar uma visão mais proativa com a adoção da avaliação ambiental estratégica e o desenvolvimento de novos indicadores ambientais que permitam monitorar a evolução da ecoeficiência da sociedade. É importante, ainda, identificar ferramentas ou tecnologias de base socioambiental relacionadas ao desenvolvimento sustentável e responsabilidade total, bem como às tendências de códigos voluntários setoriais e políticas públicas emergentes nos países desenvolvidos, relacionados à visão sistêmica de produção e gestão integrada de resíduos sólidos (PNRS, 2010).Portanto, a implantação de processos de segregação dos diferentes tipos de resíduos em sua fonte e no momento de sua geração conduz certamente à minimização de resíduos, em especial àqueles que requerem um tratamento prévio à disposição final.

A gestão compreende as ações referentes às tomadas de decisões nos aspectos administrativos, operacional, financeiro, social e ambiental. $\mathrm{O}$ gerenciamento deve abranger todas as etapas de planejamento dos recursos físicos, dos recursos materiais e da capacitação dos recursos humanos envolvidos no manejo dos RSU. Com base nisso, o presente trabalho tem por objetivo realizar um estudo de caso em uma unidade de triagem de 
resíduos sólidos urbanos, para fins de gerenciamento dos resíduos sólidos.

\section{METODOLOGIA DO TRABALHO}

\section{I Caracterização do consórcio}

O Consórcio Intermunicipal de Gestão de Resíduos Sólidos - CIGRES, foi fundado em 14 de setembro de 2001 e registrado sob CNPJ ${ }^{\circ}$ 07.363.412/0001-35, constitui-se sob a forma de associação pública, com personalidade jurídica de direito público e de natureza autárquica intermunicipal, sem fins lucrativos, atendendo as normas da Lei $\mathrm{n}^{\circ}$ 11.107, de 06.04.2005. Localiza-se no município de Seberi/RS, na BR 386, Km 43, Linha Osvaldo Cruz, telefone para contato (55) 99320756. Tendo como responsável técnico do PGRS o Senhor Odilon Sabino, e o Responsável legal é o órgão Estadual sendo a Fundação Estadual de Proteção Ambiental Henrique Luiz Roessler - RS (FEPAM).

Hoje atende 29 municípios da região do Alto Médio Uruguai, formada pela Zona da Produção e Região Celeiro, sendo eles: Ametista do Sul, Boa Vista das Missões, Caiçara, Cerro Grande, Coronel Bicaco, Cristal do Sul, Derrubadas, Dois Irmãos das Missões, Erval Seco, Frederico Westphalen, Irai, Jaboticaba, Lajeado do Bugre, Miraguaí, Novo Tiradentes, Palmitinho,
Pinhal, Pinheirinho do Vale, Redentora, Rodeio Bonito, Sagrada Família, São Pedro das Missões, Seberi, Taquaruçu do Sul, Tenente Portela, Vicente Dutra, Vista Alegre e Vista Gaúcha e Redentora, conforme ilustra a Figura 2.

Empreendimento Licenciado através da LO No 9304/2006-DL, autorizado a promover a operação relativa à atividade de Destinação de Resíduos Sólidos Urbanos, através de Central de Triagem e Compostagem com Aterro Sanitário e Lagoas de Tratamento. Localiza-se em uma área de 7,77 hectares atende a uma população urbana de 85.925 habitantes, cobre uma área de 4.883,60 $\mathrm{Km}^{2}$ e recebe uma média mensal de $1.161 .727,45$ $\mathrm{Kg}$ de resíduos sólidos urbanos. Possui como estrutura física: um prédio com $128,22 \mathrm{~m}^{2}$ destinado a administração/ balança, refeitório, banheiros e vestiários; um pavilhão de triagem com 1.964,82 $\mathrm{m}^{2}$ com duas linhas de triagem, 5 prensas enfardadeiras espaço para depósito e banheiros com vestiário; um pavilhão de peneiramento com $182,00 \mathrm{~m}^{2} \mathrm{com}$ uma peneira rotativa; pátio de compostagem com área de $13.000,00 \mathrm{~m}^{2}$, espaço para três células de aterro sanitário com capacidade final de 110.000,00 $\mathrm{m}^{3}$ e lagoas de tratamento do percolado composta de duas unidades anaeróbicas e uma facultativa.

A figura 1 ilustra o fluxograma do processo de recebimento de resíduos no consórcio.

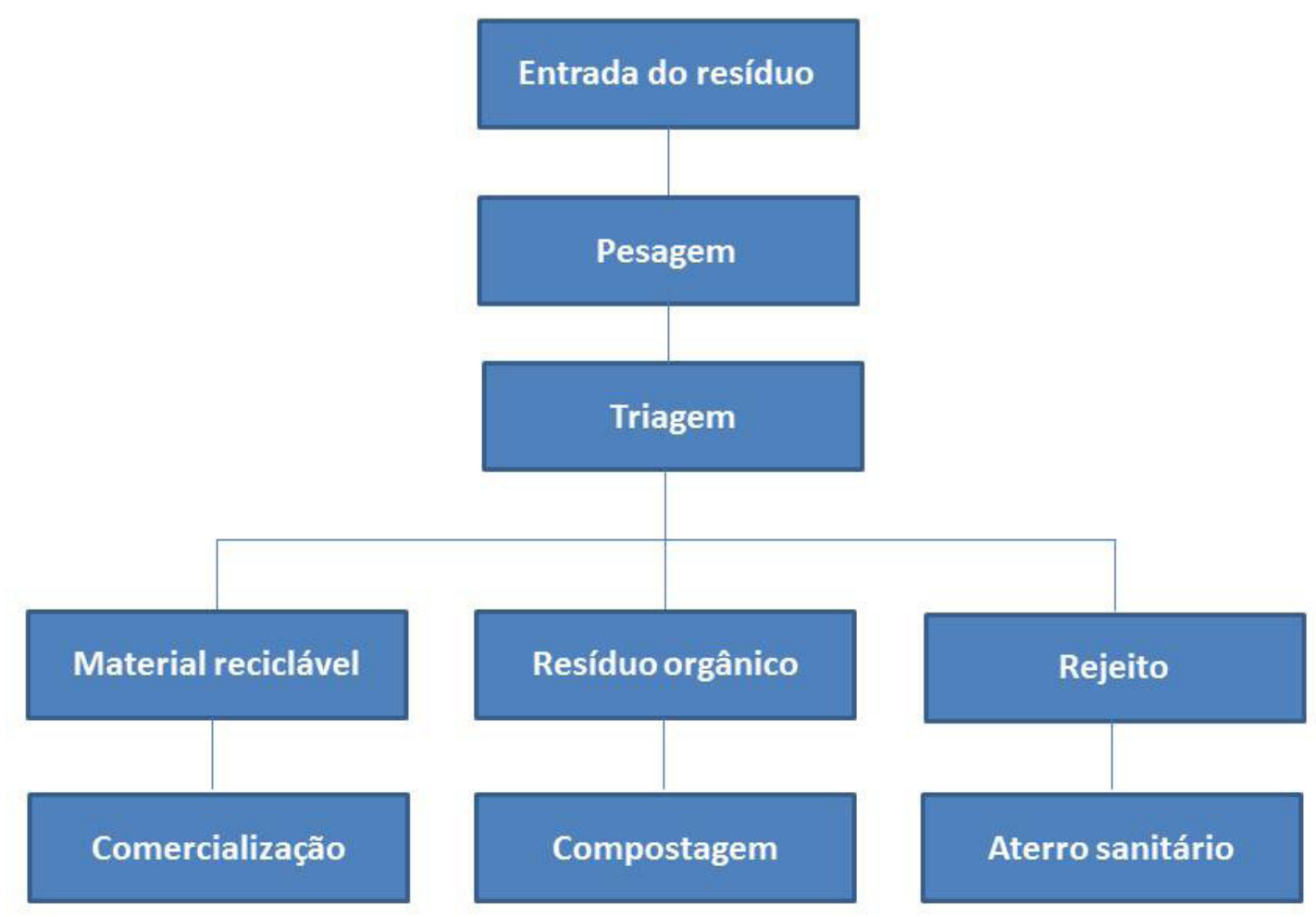

Figura 1. Fluxograma do processo de recebimento de resíduos. 


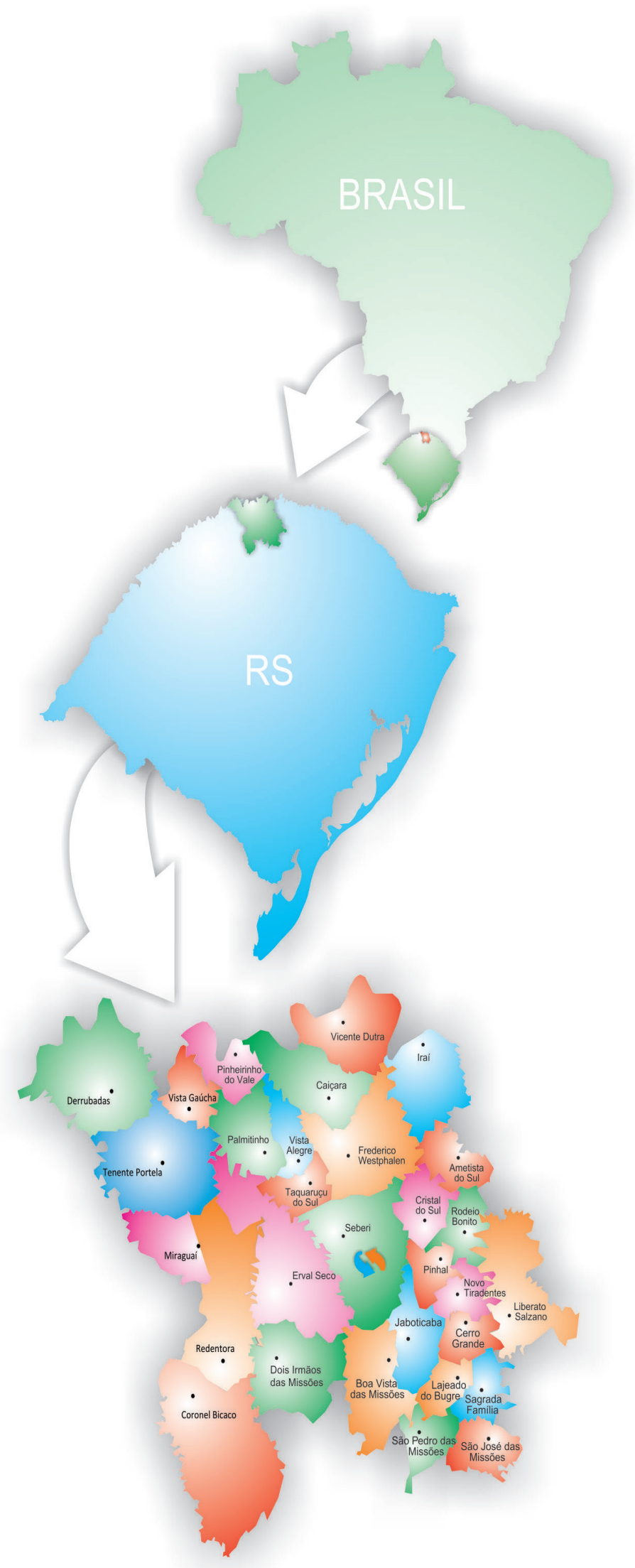

Figura 2. Localização e municípios que formam o consórcio 


\subsection{Diagnóstico da situação atual}

O consórcio CIGRES opera atendendo 29 municípios que juntos somam 164.228 habitantes (urbano e rural). Destes 29 municípios nenhum possui um sistema de coleta seletiva implantada ou que estejam em operação. Alguns municípios operam seu próprio sistema de coleta de resíduos e outros terceirizaram ambos efetuam o recolhimento nos municípios e os transportam até a sede do consórcio.

Os resíduos de saúde são recolhidos por empresas licenciadas, possuindo um contrato de prestação de serviço com as administrações municipais, onde estes resíduos são recolhidos e transportados para um local licenciado, sendo sua periodicidade estipulada por contrato e de acordo com sua produção.

Os resíduos industriais, e da construção civil, na sua grande maioria por serem municípios de pequeno porte, apresentam uma pequena geração destes tipos de resíduos, ficando seu controle e encaminhamento mantidos pelas empresas geradoras. Este controle está sendo feito pelas administrações municipais que na sua grande maioria já possuem a Secretária do meio Ambiente e tem condições de Licenciamento de pequenas atividades a nível municipal.

Os resíduos perigosos como pilhas, baterias e lâmpadas, na sua grande maioria são descartadas juntas com os resíduos domiciliares e ou comerciais. Os materiais separados no consórcio são acondicionados de forma que não cause danos à saúde e em seguida são recolhidos por empresa licenciada, sendo emitido um laudo do tipo de material recolhido, sua quantidade e seu destino.

\subsection{Caracterização dos municípios}

Os municípios integrantes do CIGRES localizam-se na região noroeste do estado do Rio Grande do Sul, abrangendo as microrregiões de Frederico Westphalen e Três Passos. A região tem parte de sua economia voltada para a produção agrícola (milho, soja, trigo), pecuária leiteira, criação de suínos, aves e parte na agricultura familiar, onde tem uma maior concentração de pessoas, sendo alguns municípios essencialmente voltados para a agricultura familiar. Apresentam pequenas indústrias e alguns segmentos de prestação de serviços.

Em termos geográficos, temos um extenso planalto, que se inclina, num plano, para o Rio Uruguai, apresentando em algumas localidades relevo acidentado e terras "dobradas". A composição do solo se caracteriza principalmente por solo argiloso de coloração avermelhada e/ou basalto em decomposição.

As cidades em sua grande maioria de porte pequeno não atingindo 4.000,00 habitantes, apresentam uma estrutura urbana simplificada, na sua grande maioria possuem vias calçadas e/ou asfaltadas, abastecimento de água e luz, apresentando uma pequena parcela de rede de esgoto pluvial e esgoto residencial. Com relação ao resíduo sólido urbano os municípios são responsáveis pelo seu recolhimento, sendo que alguns possuem este processo terceirizado e outros o realizam com a estrutura do próprio município, não existindo nenhum controle. Nos municípios não existe coleta seletiva e estrutura para a execução deste processo, sendo apenas padronizados os dias de coleta.

\subsection{Legislações e aplicações}

Referente às legislações aplicadas no Consórcio Intermunicipal de Gestão de Resíduos sólidos, estão citadas no quadro abaixo (Quadro 1), todas as Leis, Resoluções e Decretos vinculadas desde a instalação do empreendimento até o funcionamento adequado dentro de todas as normas, minimizando ou até mesmo eliminando os riscos de poluição e contaminação ambiental.

\section{RESULTADOS E DISCUSSÃO}

\section{I Resíduos gerados}

Os resíduos sólidos recicláveis, recolhidos pelo CIGRES, são enfardados e/ou acondicionados para serem comercializados para as indústrias beneficiadoras. A matéria orgânica é encaminhada para o pátio de compostagem para sofrer o processo de decomposição, ocorrendo a transformação em um composto orgânico, que pode ser utilizado como adubo orgânico pela população. O material destinado ao aterro sanitário é enfardado ou levado "solto" até as células do aterro e logo após coberto por uma camada de terra. Os restos de madeira e podas atualmente ficam depositados no pátio de compostagem onde passam pelo processo de decomposição.

As etapas do processo realizadas pelo consórcio geram, em função da forma que são realizadas, percolado com grandes concentrações de carga orgânica e outros elementos (lixiviado). Estas águas são recolhidas e encaminhadas para a estrutura de tratamento, que é formada por duas lagoas anaeróbicas e uma lagoa facultativa.

No Quadro 2 (abaixo), tem-se a relação dos municípios e seus respectivos pesos de RSU entregues entre 2007 a 2011. 
Quadro 1. Legislação Vigente

\begin{tabular}{|c|c|c|}
\hline $\begin{array}{l}\text { Diploma } \\
\text { Federado }\end{array}$ & Número/ Ano & Conteúdo \\
\hline Decreto Federal & $3.365 / 41$ & Dispõe sobre desapropriação por utilidade pública. \\
\hline Lei Federal & $6.766 / 79$ & $\begin{array}{l}\text { Dispõe sobre o Parcelamento do Solo Urbano e dá outras } \\
\text { Providências. }\end{array}$ \\
\hline Lei Federal & $10.257 / 01$ & $\begin{array}{l}\text { Regulamenta os arts. } 182 \text { e } 183 \text { da Constituição Federal, } \\
\text { estabelece diretrizes gerais da política urbana e dá outras } \\
\text { providências. }\end{array}$ \\
\hline Resolução CONAMA & $283 / 01$ & $\begin{array}{l}\text { Dispõe sobre o tratamento e a destinação final dos resíduos dos } \\
\text { serviços de saúde. }\end{array}$ \\
\hline Resolução CONAMA & $307 / 02$ & $\begin{array}{l}\text { Estabelece diretrizes, critérios e procedimentos para a gestão dos } \\
\text { resíduos da construção civil. }\end{array}$ \\
\hline Resolução CONAMA & $303 / 02$ & $\begin{array}{l}\text { Dispõe sobre parâmetros da Área de Preservação Permanente - } \\
\text { APP. }\end{array}$ \\
\hline Lei Federal & $11.107 / 05$ & Lei de Consórcios Públicos. \\
\hline $\begin{array}{l}\text { Resolução Conselho } \\
\text { Cidades }\end{array}$ & 25 e $34 / 05$ & $\begin{array}{l}\text { Dispõe sobre a participação e controle social na elaboração e } \\
\text { acompanhamento do Plano Diretor Municipal. }\end{array}$ \\
\hline $\begin{array}{l}\text { Resolução Conselho } \\
\text { Cidades }\end{array}$ & 75/09 & $\begin{array}{l}\text { Trata da Política e do conteúdo Mínimo dos Planos de } \\
\text { Saneamento Básico. }\end{array}$ \\
\hline Lei Federal & $11.124 / 05$ & Lei do Sistema Nacional de Habitação de Interesse Social. \\
\hline Lei Federal & 11.445/07 & $\begin{array}{l}\text { Estabelece diretrizes nacional para o saneamento básico; altera } \\
\text { as Leis } n^{\circ} 6.766 / 79,8.036 / 90,8.666 / 93,8.987 / 95 \text {; revoga a Lei } n^{\circ} \\
6.528 \text {, de } 11 \text { de maio de } 1978 \text {; e dá outras providências. }\end{array}$ \\
\hline Lei Federal & 12.305/10 & Dispõe sobre as Políticas Públicas de Resíduos Sólidos. \\
\hline Norma Regulamentadora & NR6/ 2001 & Equipamento de proteção Individual. \\
\hline Decreto Federal & $7.404 / 10$ & $\begin{array}{l}\text { Regulamenta a Lei } n^{\circ} 12.305 \text {, de } 2 \text { de agosto de } 2010 \text {, que } \\
\text { institui a Política Nacional dos Resíduos Sólidos - PNRS, cria o } \\
\text { Comitê Interministerial da PNRS e o Comitê Orientador para } \\
\text { a implantação dos Sistemas de Logística Reversa, e dá outras } \\
\text { providências. }\end{array}$ \\
\hline Lei Estadual & $11.520 / 00$ & Código Estadual do Meio Ambiente. \\
\hline Lei Estadual & $12.037 / 00$ & Lei Estadual de Saneamento Básico. \\
\hline Decreto Estadual & $42.810 / 04$ & $\begin{array}{l}\text { Institui o Programa Ação Total de Regularização Fundiária com } \\
\text { Inclusão Social. }\end{array}$ \\
\hline Decreto Estadual & $128 / 06$ & $\begin{array}{l}\text { Dispõe sobre a fixação de Padrões de Emissão de Efluentes } \\
\text { Líquidos para fontes de emissão que lancem seus efluentes em } \\
\text { águas superficiais no Estado do Rio Grande do Sul. }\end{array}$ \\
\hline Lei Estadual & $13.017 / 08$ & $\begin{array}{l}\text { Dispõe sobre o Sistema Estadual de Habitação de Interesse Social } \\
\text { - SEHIS, o Fundo Estadual de Habitação de Interesse Social - FEHIS } \\
\text { e o Conselho Gestor do FEHIS. }\end{array}$ \\
\hline
\end{tabular}

Fonte: FAMURS (2011). 
Quadro 2. Total de resíduos dos municípios consorciados (2007 à 2011).

\begin{tabular}{|c|c|c|c|c|c|}
\hline Município & 2007 & 2008 & 2009 & 2010 & 2011 \\
\hline Ametista do Sul & & $374.120,00$ & $514.365,00$ & $545.205,00$ & $587.920,00$ \\
\hline Boa Vista das M. & $80.780,00$ & $160.410,00$ & $170.300,00$ & $156.524,00$ & $167.291,00$ \\
\hline Caiçara & - & - & $304.770,00$ & $252.080,00$ & $253.408,00$ \\
\hline Cerro Grande & - & - & $100.340,00$ & $105.970,00$ & $125.830,00$ \\
\hline Coronel Bicaco & - & - & - & $493.580,00$ & $544.980,00$ \\
\hline Cristal do Sul & - & $256.992,00$ & $264.520,00$ & $210.310,00$ & $158.380,00$ \\
\hline Derrubadas & - & - & $68.555,00$ & $142.890,00$ & $117.025,00$ \\
\hline Dois Irmãos das M. & $44.660,00$ & $106.400,00$ & $104.695,00$ & $111.440,00$ & $58.700,00$ \\
\hline Erval Seco & $172.830,00$ & $364.300,00$ & $412.176,00$ & $469.470,00$ & 497.999,00 \\
\hline Frederico W. & $3.992 .390,0$ & $5.414 .822,00$ & $5.032 .725,00$ & $5.058 .251,00$ & $5.208 .142,00$ \\
\hline Iraí & - & $577.844,00$ & $825.760,00$ & $716.340,00$ & $808.640,00$ \\
\hline Jaboticaba & $80.500,00$ & $188.240,00$ & $174.038,00$ & $222.170,00$ & $244.510,00$ \\
\hline Lajeado do Bugre & $34.130,00$ & $82.179,00$ & $83.860,00$ & $79.020,00$ & $84.050,00$ \\
\hline Miraguaí & - & - & $67.640,00$ & $257.550,00$ & $251.015,00$ \\
\hline Novo Tiradentes & - & - & $112.038,00$ & $106.118,00$ & $108.614,00$ \\
\hline Palmitinho & - & - & $436.160,00$ & $498.611,00$ & $614.480,00$ \\
\hline Pinhal & - & $204.590,00$ & $235.550,00$ & $258.650,00$ & $250.054,00$ \\
\hline Pinheirinho do V. & - & - & $237.250,00$ & $274.210,00$ & $320.248,00$ \\
\hline Redentora & - & - & $226.705,00$ & $323.830,00$ & $314.540,00$ \\
\hline Rodeio Bonito & $429.390,00$ & $688.440,00$ & $605.400,00$ & $620.049,00$ & $605.317,00$ \\
\hline Sagrada Família & - & - & $34.070,00$ & $138.310,00$ & $144.370,00$ \\
\hline São Pedro Das M. & - & - & - & $77.800,00$ & $82.400,00$ \\
\hline Seberi & $820.704,00$ & $1.128 .475,00$ & $929.627,00$ & $1.078 .772,00$ & $1.164 .080,00$ \\
\hline Taquaruçu do Sul & $78.360,00$ & $156.360,00$ & $186.319,00$ & $193.411,00$ & $232.190,000$ \\
\hline Tenente Portela & - & - & $736.350,00$ & $1.228 .350,00$ & $1.356 .450,00$ \\
\hline Vicente Dutra & - & $535.750,00$ & $262.622,00$ & $264.360,00$ & $291.820,00$ \\
\hline Vista Alegre & $105.710,00$ & $180.340,00$ & $183.480,00$ & $192.500,00$ & $226.630,00$ \\
\hline Vista Gaúcha & - & - & $34.650,00$ & $168.730,00$ & $188.570,00$ \\
\hline São José Das M. & - & - & - & - & $60.980,00$ \\
\hline Liberato Salzano & - & - & - & - & $114.760,00$ \\
\hline TOTAL & $5.839 .454,00$ & $10.419 .262,00$ & $12.343 .965,00$ & $14.244 .501,00$ & $15.183 .393,0$ \\
\hline
\end{tabular}


Com a grande quantidade de resíduos recebidos diariamente pelo CIGRES, a agilidade dos funcionários e o bom desempenho perante falta de conscientização da população, devido a inexistên- cia de uma separação adequada diariamente são retirados quantidades significativa de materiais recicláveis aos quais são observados no Quadro 3.

Quadro 3. Percentuais dos materiais reciclados, CIGRES.

\begin{tabular}{|c|c|c|c|c|c|c|c|c|}
\hline \multirow{3}{*}{$\begin{array}{l}\text { PRODUTO } \\
\text { Papelão }\end{array}$} & \multicolumn{2}{|c|}{ TOTAL } & \multicolumn{2}{|c|}{ MÉDIA MENSAL } & \multirow{2}{*}{\multicolumn{2}{|c|}{ CLASSE - Kg }} & \multirow{2}{*}{\multicolumn{2}{|c|}{ CLASSE- R\$ }} \\
\hline & PESO & TOTAL R\$ & PESO & TOTAL R\$ & & & & \\
\hline & 322.385 & 89.600 & 26.865 & 7.466 & \multirow{3}{*}{$\begin{array}{l}\vec{u} \\
\frac{\vec{a}}{\Delta}\end{array}$} & \multirow{4}{*}{$34,65 \%$} & \multirow{3}{*}{$\begin{array}{l}\vec{u} \\
\frac{u}{a}\end{array}$} & \multirow{4}{*}{$21,08 \%$} \\
\hline Papel Misto & 345.830 & 37.351 & 28.819 & 3.112 & & & & \\
\hline Papel Branco & 74.546 & 27.451 & 6.212 & 2.287 & & & & \\
\hline Tetra Park & 50.370 & 10.074 & 4.197 & 839 & 793.131 & & 164.476 & \\
\hline Pet & 180.867 & 208.694 & 15.072 & 17.391 & \multirow{7}{*}{ 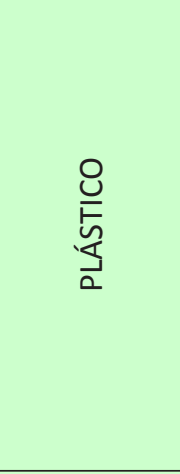 } & \multirow{8}{*}{$40,44 \%$} & \multirow{7}{*}{$\frac{0}{0}$} & \multirow{8}{*}{$68,38 \%$} \\
\hline Resina & 36.910 & 10.430 & 3.075 & 869 & & & & \\
\hline Branco Garraf. & 81.500 & 90.819 & 6.791 & 7.568 & & & & \\
\hline Colorido Garraf. & 65.310 & 55.319 & 5.442 & 4.609 & & & & \\
\hline Balde/Bacia & 44.660 & 21.003 & 3.721 & 1.750 & & & & \\
\hline Rafia & 63.750 & 12.750 & 5.312 & 1.062 & & & & \\
\hline Misto Mole & 445.357 & 131.423 & 37.113 & 10.951 & & & & \\
\hline Pvc & 7.460 & 2.984 & 621 & 248 & 925.814 & & 533.423 & \\
\hline Lata Prensada & 112.671 & 19.154 & 9.389 & 1.596 & \multirow{7}{*}{$\begin{array}{l}\overrightarrow{\overleftarrow{K}} \\
\stackrel{\vec{\Sigma}}{\Sigma}\end{array}$} & \multirow{8}{*}{$10,87 \%$} & \multirow{7}{*}{ 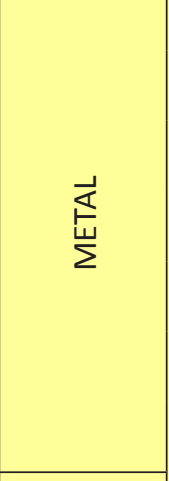 } & \multirow{8}{*}{$8,54 \%$} \\
\hline Sucata Solta & 98.990 & 9.899 & 8.249 & 824 & & & & \\
\hline Alumínio Latinha & 13.700 & 19.338 & 1.141 & 1.611 & & & & \\
\hline Alumínio Grosso & 4.002 & 6.803 & 333 & 566 & & & & \\
\hline Perfume & 2.221 & 2.638 & 185 & 219 & & & & \\
\hline Fio Cobre Sujo & 2.713 & 4.070 & 226 & 339 & & & & \\
\hline Motor & 14.030 & 4.209 & 1.169 & 350 & & & & \\
\hline Inox & 511 & 511 & 42 & 42 & 248.839 & & 66.623 & \\
\hline Vidro Moído & 304.090 & 8.966 & 25.340 & 747 & \multirow{5}{*}{ 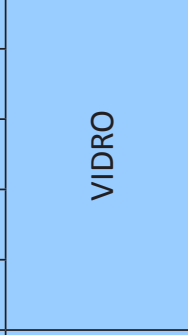 } & \multirow{6}{*}{$14,04 \%$} & \multirow{5}{*}{$\begin{array}{l}\text { 옹 } \\
\text { ำ } \\
\text { > }\end{array}$} & \multirow{6}{*}{$2,00 \%$} \\
\hline Vidros Diversos-Und. & 47.392 & 4.280 & 3.949 & 356 & & & & \\
\hline Garrafas 51-Und. & 5.697 & 1.467 & 474 & 122 & & & & \\
\hline Velho Barreiro-Und. & 4.623 & 693 & 385 & 57 & & & & \\
\hline Garrafão Com Capa & 50 & 50 & 4 & 4 & & & & \\
\hline Garrafão S/ Capa & 220 & 110 & 18 & 9 & 321.484 & & 15.568 & \\
\hline Total & 2.289 .268 & 780.092 & 190.772 & 65.007 & 2.289.268 & $100 \%$ & 780.092 & $100 \%$ \\
\hline
\end{tabular}


Quadro 4. Total de Resíduos dos municípios entre os anos de 2007 e 2011.

\begin{tabular}{|c|c|c|}
\hline ANO & RESÍDUO RECEBIDO $(\mathrm{Kg})$ & MATERIAL RECICLADO (R\$) \\
\hline 2007 & $5.839 .454,00$ & $\mathrm{R} \$ 267.173,38$ \\
\hline 2008 & $10.419 .262,00$ & $\mathrm{R} \$ 331.453,52$ \\
\hline 2009 & $12.343 .825,00$ & $\mathrm{R} \$ 492.092,60$ \\
\hline 2010 & $14.244 .501,00$ & $\mathrm{R} \$ 530.185,55$ \\
\hline 2011 & $15.183 .393,00$ & $\mathrm{R} \$ 779.093,99$ \\
\hline TOTAL & $\mathbf{5 8 . 0 3 0 . 7 9 9 , 0 0}$ & $\mathbf{R} \mathbf{2 . 1 3 2 . 8 2 5 , 6 6}$ \\
\hline
\end{tabular}

No Quadro 4 encontra-se o total de resíduos entre os anos de 2007 a 2011 de todos os municípios que constituem o consórcio Intermunicipal CIGRES.

\subsection{Plano de movimentação de resíduos}

Como forma de caracterização socioeconômica o Quadro 5 ilustra a relação dos municípios com suas populações e sua contribuição de

\begin{tabular}{|c|c|c|c|c|}
\hline \multicolumn{5}{|c|}{ Quadro 5. População Urbana e Rural Por Municípios } \\
\hline Municípios & Pop. Urbana & Pop. Rural & Pop. Total & Média Mensal - Kg \\
\hline Ametista do Sul & $3.811,00$ & $3.512,00$ & $7.323,00$ & $44.353,18$ \\
\hline Boa Vista das M. & 886,00 & $1.228,00$ & $2.114,00$ & $12.581,27$ \\
\hline Caiçara & $1.594,00$ & $3.477,00$ & $5.071,00$ & $20.897,27$ \\
\hline Cerro Grande & 830,00 & $1.587,00$ & $2.417,00$ & $8.586,36$ \\
\hline Coronel Bicaco & $5.068,00$ & $2.680,00$ & $7.748,00$ & $40.280,91$ \\
\hline Cristal do Sul & 931,00 & $1.895,00$ & $2.826,00$ & $17.555,45$ \\
\hline Derrubadas & 901,00 & $2.289,00$ & $3.190,00$ & $11.785,45$ \\
\hline Dois Irmãos das M. & $1.094,00$ & $1.063,00$ & $2.157,00$ & $10.019,09$ \\
\hline Erval Seco & $3.437,00$ & $4.441,00$ & $7.878,00$ & $37.354,55$ \\
\hline Frederico $\mathrm{W}$. & $23.338,00$ & $5.510,00$ & $28.848,00$ & $412.227,55$ \\
\hline Iraí & $4.457,00$ & $3.621,00$ & $8.078,00$ & $58.160,00$ \\
\hline Jaboticaba & $1.487,00$ & $2.624,00$ & $4.111,00$ & $18.065,45$ \\
\hline Lajeado do Bugre & 706,00 & $1.781,00$ & $2.487,00$ & $6.459,09$ \\
\hline Miraguaí & $2.069,00$ & $2.786,00$ & $4.855,00$ & $21.023,64$ \\
\hline Novo Tiradentes & 654,00 & $1.623,00$ & $2.277,00$ & $8.853,45$ \\
\hline Palmitinho & $3.393,00$ & $3.527,00$ & $6.920,00$ & $40.581,91$ \\
\hline Pinhal & $1.290,00$ & $1.225,00$ & $2.515,00$ & $21.111,82$ \\
\hline Pinheirinho do V. & 915,00 & $3.588,00$ & $4.503,00$ & $22.272,73$ \\
\hline Redentora & $3.002,00$ & $7.220,00$ & $10.222,00$ & $26.728,18$ \\
\hline Rodeio Bonito & $4.310,00$ & $1.433,00$ & $5.743,00$ & $51.336,27$ \\
\hline Sagrada Família & 785,00 & $1.810,00$ & $2.595,00$ & $11.308,18$ \\
\hline São Pedro das M. & 532,00 & $1.354,00$ & $1.886,00$ & $6.322,73$ \\
\hline Seberi & $5.923,00$ & $4.979,00$ & $10.902,00$ & $87.491,00$ \\
\hline Taquaruçu do Sul & $1.164,00$ & $1.806,00$ & $2.970,00$ & $16.330,09$ \\
\hline Tenente Portela & $8.847,00$ & $4.869,00$ & $13.716,00$ & $99.541,82$ \\
\hline Vicente Dutra & $2.351,00$ & $2.934,00$ & $5.285,00$ & $21.373,64$ \\
\hline Vista Alegre & $1.185,00$ & $1.647,00$ & $2.832,00$ & $15.325,45$ \\
\hline Vista Gaúcha & 965,00 & $1.794,00$ & $2.759,00$ & $13.500,91$ \\
\hline Total & $85.925,00$ & $78.303,00$ & $164.228,00$ & $1.161 .727,45$ \\
\hline
\end{tabular}


resíduos a relação dos municípios integrantes do consórcio com dados sócio-econômicos.Nesta etapa descreveu-se a situação atual destes resíduos, indicando sua origem, seu volume, a caracterização dos resíduos e as formas de destinação e disposição final adotadas.

O resíduo a ser atendido pelo PGRS é especificamente de origem doméstica, gerado nas residências localizadas tanto na área urbana quanto rural dos municípios integrantes do consórcio, sendo especificamente materiais orgânicos, secos, recicláveis e não recicláveis (destinados ao aterro sanitário).

A unidade recebe cerca de $1.161 .727,45 \mathrm{Kg}$ de material por mês, onde praticamente todo este material é encaminhado para as esteiras de triagem, entorno de $99,65 \%$. Neste processo ocorre a separação do material reciclável - 18,91\%, material destinado ao aterro sanitário $(21,57 \%)$, material orgânico $(59,49 \%)$ e restos de madeira $(0,38 \%)$.

Neste PGRS são atendidos especificamente os geradores dos resíduos sólidos urbanos de característica doméstica, sendo os resíduos dos serviços públicos de saneamento básico.

O local de estocagem temporária dos resíduos é no pátio onde há um selamento com cimento do solo e valas de escoamento superficial do lixiviado, evitando contaminação com o solo, onde após algumas horas são depositados em uma esteira onde os materiais são devidamente separados e corretamente seus rejeitos dispostos em células do aterro.

Os resíduos devidamente separados são prensados e quando estiver em grande quantidade são vendido a terceiros ou a indústrias que compram o produto tanto para reúso como para reciclagem conforme indica a Figura 3, dentre os mais comercializados estão alumínio, vidro e plásticos assim como caixa de leite e frascos de aerossóis.

O transporte é terceirizado, ou seja, cada prefeitura é responsável pelo transporte e transbordo de seu resíduo, o consórcio não tem responsabilidade alguma com o transporte, apenas a partir do momento que o "lixo" adentra nos seus domínios.

\subsection{Plano de gerenciamento}

O plano de gerenciamento busca mostrar as ações que já estão sendo tomadas no aterro, e também apontar alternativas para que sejam gerenciados os resíduos sempre buscando a minimização e separação adequada na fonte geradora para que não se torne cada ver maior o problema da destinação final adequada, sem esquecer que a reutilização e a reciclagem também contribuem muito nesse processo.

Programa de redução na fonte geradora

O sistema de gestão de resíduos deverá privilegiar através da educação ambiental, soluções voltadas para a minimização da geração, a segregação, o reaproveitamento e a reciclagem dos resíduos sólidos gerados.

Para a realização desse tipo de atividade o consórcio realiza palestras e passadas nas escolas das cidades que o abastecem, promovendo uma

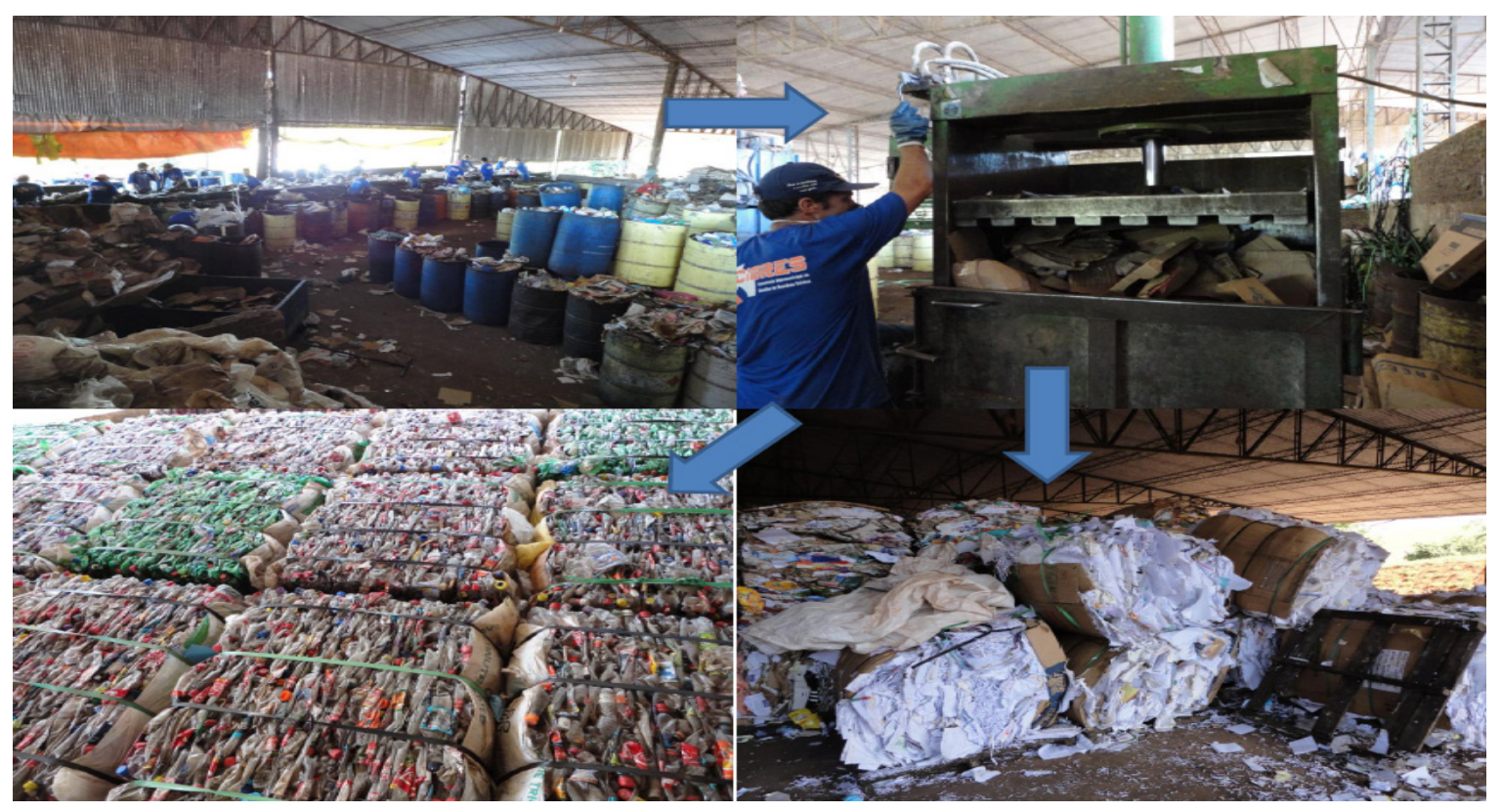

Figura 3. Material separado e prensado em blocos para a venda. 
educação para a segregação correta e a reutilização visando à minimização na fonte.

\subsection{Acondicionamento}

Após a segregação correta dos resíduos, estes permanecem por pouco tempo no galpão, uma vez que a fração orgânica segue para o pátio de compostagem, e o lixo seco é disposto nas células do aterro.

Desta forma os demais tipos de resíduos são separados e destinados da seguinte maneira:

Plástico duro: esse plástico de cor branco leitoso é prensado e acondicionado em fardos, até ser vendido para atravessadores, que encaminham às empresas que fazem a limpeza e reciclagem do material.

Papel: o papel é separado em Papelão, papel branco, e papel colorido, seguindo cada um para um tipo de reciclagem após ser prensado e armazenado na forma de fardos. O papel branco é vendido para uma empresa do município de Seberi-RS, que transforma o mesmo em papel higiênico.

Garrafas Pet: essas garrafas são separadas de acordo com sua cor, frascos de detergente e garrafas de óleo de cozinha, prensadas e compactadas em fardos, até serem comercializadas para empresas de reciclagem.

Lâmpadas, pilhas, baterias e lixo hospitalar: como o consórcio não é licenciado para receber esse tipo de material, mas eventualmente devido a falta de informação da população esses resíduos acabam chegando até o aterro, então esses resíduos são separados e encaminhados até o aterro da CETRIC em Chapecó-SC, que é licenciado para o recebimento de tais componentes. Enquanto aguardam esse encaminhamento, as pilhas e baterias são acondicionadas em tambores de plástico, o lixo hospitalar em tambores de lata, e as lâmpadas são acumuladas em um local com piso impermeabilizado.

Eletroeletrônicos: esse tipo de sólido como computadores, televisões, rádios e afins, é desmontado no aterro, e a parte aproveitável na reciclagem, como plástico, vidro, cobre e outros, são vendidos, e o restante, é disposto no aterro.

Periodicamente os funcionários recebem e são orientados a utilizar os Equipamentos de Proteção Individual (EPI's), que tem a função de prevenir acidentes ou lesões devido ao trabalho insalubre que os mesmos enfrentam diariamente. Os funcionários recebem os seguintes equipamentos de segurança:

- Capacete;

- camisa;

- calça;

- mangote,

- calçado de couro com solado e biqueira de aço;

- luvas;

- avental;

- óculos;

- protetor auricular.

O termo logística reversa é um instrumento de desenvolvimento econômico e social caracterizado por um conjunto de ações, procedimentos

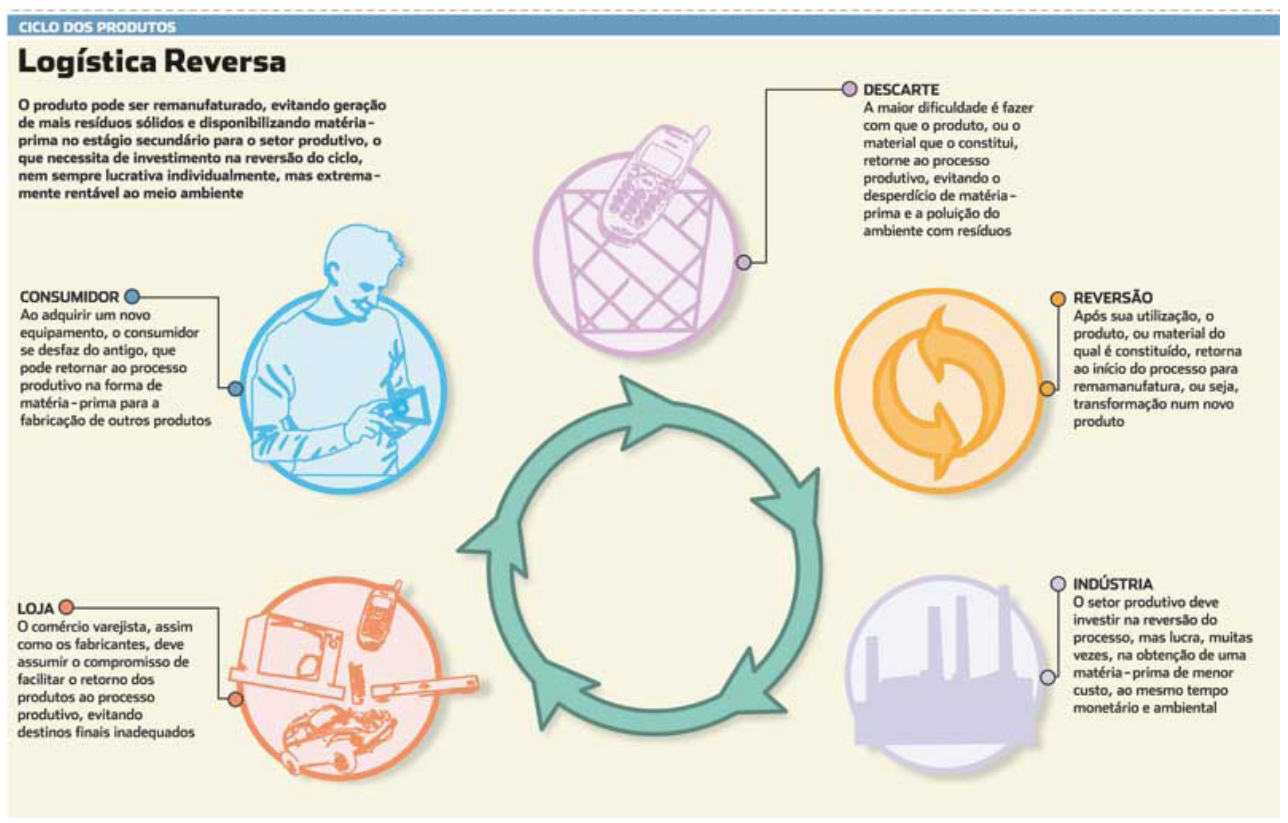

Figura 4. Esquema da logística reversa.

Fonte: http://j2da.wordpress.com/category/sustentabilidade/ 


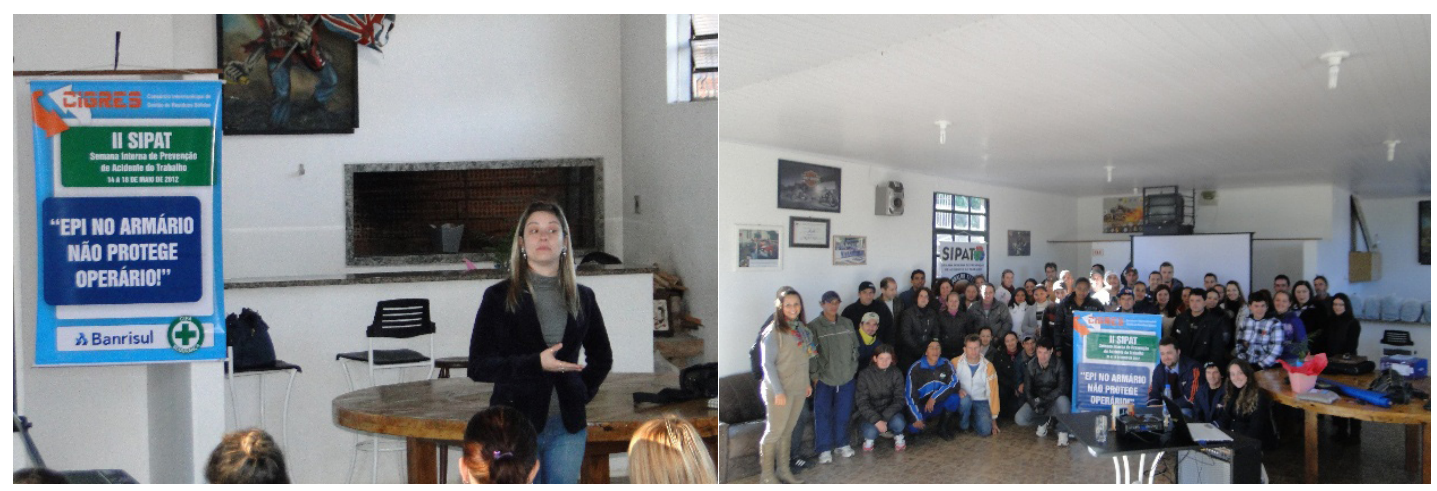

Figura 5. Seminário interno de prevenção de acidentes.

e meios destinados a viabilizar a coleta e a restituição dos resíduos sólidos ao setor empresarial, para reaproveitamento, em seu ciclo ou em outros ciclos produtivos, ou outra destinação final ambientalmente adequada. A Figura 4 ilustra o esquema da logística reversa.

A cada três meses a direção do consórcio organiza o Seminário Interno de Prevenção de Acidentes - SIPAT, onde convoca os funcionários e expõe sobre a importância da utilização do EPI adequado e de outras medidas de segurança na prevenção de acidentes, conforme Figura 5.

Coleta/transporte interno dos resíduos

Para o sistema de coleta e transporte interno, o consórcio deve contar com o auxílio de no mínimo uma carregadeira e um caminhão caçamba, além de profissionais treinados para operar tais máquinas, assim realizando tanto o transporte dos resíduos e a selagem das camadas de resíduo com camadas de solo.

\subsection{Estocagem rápida}

Para a estocagem rápida, antes (Figura 5a) e após (Figura $5 b$ ) os resíduos passarem pela esteira de separação, os mesmos ficam estocados em um pavilhão coberto com piso impermeabilizado, esperando assim o momento de serem dispostos nos locais adequados para cada tipo de resíduo.

\subsection{Armazenamento}

O armazenamento dos resíduos que não seguem para as células do aterro acontece em um pavilhão coberto com piso impermeabilizado e calhas para a coleta do lixiviado, dispondo esse espaço de 1470 metros quadrados.

\subsection{Pré-Tratamento}

Coleta e destinação do lixiviado

$\mathrm{O}$ aterro conta com três células para a disposição do lixo, sendo que uma já está em fase de fechamento, e outra já está sendo usada, e uma terceira, ainda não é utilizada e tem seu solo coberto pelo plantio de milho, onde posteriormente será implantada mais uma lagoa para o acúmulo do chorume.

Por ser um solo de origem bastante argilosa, e assim bastante impermeável, o mesmo não conta com uma manta para impermeabilização do solo.

O chorume é canalizado por drenos transversais, que levam o líquido das células e do pátio de compostagem até uma caixa coletora, e desta o chorume segue para as lagoas de estabilização, que são 3 , sendo 2 anaeróbias e uma facultativa. Por vezes o chorume é bombeado para fazer o

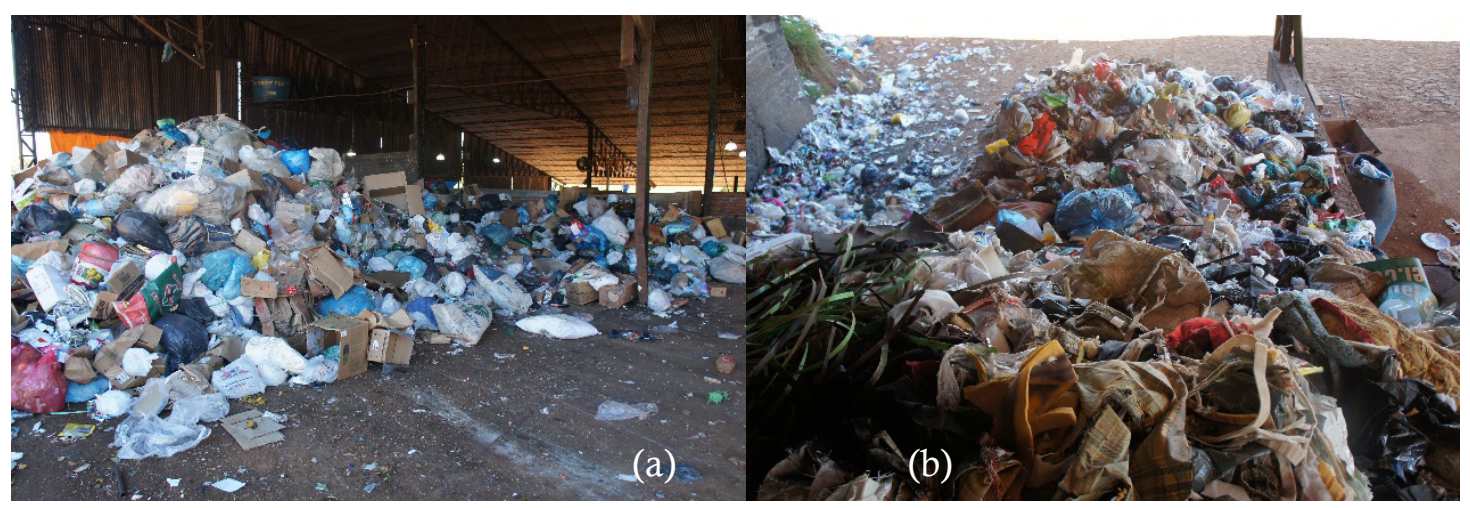

Figura 5. Resíduos antes do processo de triagem (a) e após a triagem (b). 
controle de umidade das leiras de compostagem, e outra parte serve na fertirrigação de lavouras.

\subsection{Matéria orgânica}

Esse tipo de material é encaminhado para a compostagem, onde no próprio aterro, existe um pátio para essa atividade, depois de pronto o composto, o material é comercializado como fertilizante agrícola. Devido a um período de alta precipitação pluviométrica no ano de 2009 , a compostagem deixou de funcionar normalmente, e atualmente o sistema encontra-se sobrecarregado, com um enorme volume de material acumulado, cerca de 4 a 5 mil toneladas.

\subsection{Coleta/transporte externo}

O transporte externo é terceirizado, ou seja, cada prefeitura é responsável pelo transporte e transbordo de seu resíduo, o consórcio não tem responsabilidade alguma com o transporte, apenas a partir do momento que o "lixo" adentra nos seus domínios.

A empresa CETRIC que recebe parte dos resíduos que não podem ser dispostos no CIGRES, realiza a prestação do serviço de transporte com frota e equipamentos de coleta próprios. A empresa disponibiliza caçambas estacionárias próprias, com rastreamento e seguro de danos ambientais, para o armazenamento e segregação dos resíduos Classes I, IIA e IIB. Todos os processos de coleta e transporte de resíduos seguem as diretrizes emanadas pela NBR 13221 - Transporte Terrestres de Resíduos.

\section{I0 Tratamento externo}

Dos tratamentos realizados externamente, destaca-se na CETRIC em Chapecó-SC, a operação "papa lâmpadas", tratamento dado para as lâmpadas fluorescentes.

O sistema é composto de um tambor metálico de 200 litros, com capacidade para armazenar aproximadamente 850 lâmpadas trituradas, reduz drasticamente a área de armazenagem e os riscos de estocagem; possui duplo sistema de filtragem, um para os fragmentos de vidro e pó fosfórico e outro para os gases venenosos, como o mercúrio, devolvendo à atmosfera apenas o ar descontaminado. E por funcionar com sistema de operação a vácuo, isenta o operador de quaisquer riscos de retrocesso de fragmentos e contaminação pelo vapor do mercúrio. Em anexo a licença para a localização e permanência do aterro em Chapecó-SC.

Para as pilhas e baterias, que seguem também para a CETRIC, vale lembrar que não é de obrigação do CIGRES a coleta e o recebimento das mesmas.

Estas se enquadram no art. 33 da lei $12305 / 2010$, onde diz que são obrigados a estruturar e implementar sistemas de logística reversa, mediante retorno dos produtos após o uso pelo consumidor, de forma independente do serviço público de limpeza urbana e de manejo dos resíduos sólidos, os fabricantes, importadores, distribuidores e comerciantes.

\section{I I Educação ambiental}

No que diz respeito a Educação Ambiental o consórcio pretende priorizar o desenvolvimento de atividades voltadas para a educação ambiental em conformidade com as diretrizes estabelecidas pela Política Nacional de Educação Ambiental Lei No 9.795/99 e pelo Código Estadual de Meio Ambiente.

Desta forma o consórcio realiza palestras nas escolas dos municípios consorciados e espaços com os funcionários, salientando a importância da separação correta do lixo e da minimização na fonte geradora.

\section{CONCLUSÃO}

O consórcio possui um ótimo quadro técnico, operacional e administrativo, onde o mesmo consegue, com as vendas dos materiais recicláveis, custear metade das despesas mensais. Para melhorar as condições de operação e destinação, além de otimizar o processo de triagem como um todo, o consórcio deve investir em parcerias com os municípios consorciados, para que seja feita uma melhor separação dos resíduos na fonte geradora, ou seja, nas residências.

Uma vez que o resíduo chegue já devidamente segregado ao aterro, tende a facilitar o trabalho dos funcionários e agregar mais valor aos resíduos sólidos que seguem para a reciclagem, por chegarem em melhores condições de limpeza, assim também sendo possível separar em maior quantidade.

\section{REFERÊNCIAS}

ALENCAR, M.M.M. Reciclagem de lixo numa escola pública do município de Salvador. Revista Virtual, Vol.1, n.2, p.96-113, 2005.

BRASIL. Lei Federal n 12305 de 2 de agosto de 2010. Política Nacional dos Resíduos Sólidos. 
Disponível em: http://www.planalto.gov.br/ccivil 03/ ato2007-2010/2010/lei/112305.htm. Acessado em: 14 de Junho de 2013.

COMISSÃO DE GERENCIAMENTO DE RESÍDUOS DA UFPA - COGERE/UFPA. Plano geral de gerenciamento de resíduos DA UFPA - PGGR. Belém: UFP, 2008. 115p.

FEDERAÇ̃̃O DAS ASSOCIACÕES DE MUNICÍPIOS DO RIO GRANDE DO SUL - FAMURS. Termo de Referência Para o Plano de Gestão de Resíduos Sólidos. Porto Alegre: FAMURS, 2011. 30p.

FEDERAÇÃO ESTATÍSTICA E ECONÔMICA FEE. FEE DADOS. Disponível em: http://www.fee. rs.gov.br/feedados/consulta/sel_modulo_pesquisa. asp. Acesso em: 14 de Junho de 2013.

GARCILASSO, V.P. Geração de energia elétrica a partir do biogás proveniente de aterro sanitário. 110f. 2006. Dissertação (Mestrado em Energia) - Programa de Pós-Graduação em energia, Universidade de São Paulo, São Paulo, 2006.

HIRATA, A. C. R. Os recursos hídricos subterrâneos e as novas exigências ambientais. In: Revista do Instituto Geológico, Vol.14, n.2, p.39-62, 1993.

PLANO NACIONAL DE RESÍDUOS SÓLIDOS. Versão preliminar para consulta pública, 2011. Instituto Brasileiro de Geografia e Estatística (IBGE). Disponível em: http://www.ibge.gov.br/home/. Acesso em: 15 de Julho de 2013.

TARTARI, L. C. Avaliação do processo de tratamento do chorume de aterro sanitário de Novo Hamburgo. Revista Liberato, Vol.6, n.6, p.66-74, 2005. 